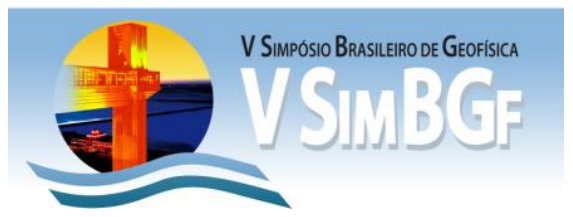

\title{
Titulo: ESTUDO GRAVIMÉTRICO PRELIMINAR DA PORÇÃO CENTRAL DA PLANÍCIE DO RECIFE/PE
}

José Ricardo Gonçalves Magalhães', UFPE; Mário Amilde Valença dos Santos², UFPE; Tiago Siqueira de Miranda², UFPE; José Antônio Barbosa ${ }^{4}$, UFPE; Jefferson Tavares Cruz Oliveira ${ }^{5}$, UFPE

Copyright 2012, SBGf - Sociedade Brasileira de Geofísica

Este texto foi preparado para a apresentação no V Simpósio Brasileiro de Geofísica, Salvador, 27 a 29 de novembro de 2012. Seu conteúdo foi revisado pelo Comite Técnico do V SimBGf, mas não necessariamente representa a opinião da SBGf ou de seus associados. É proibida a reprodução total ou parcial deste material para propósitos comerciais sem prévia autorização da SBGt.

\section{Resumo}

Dados gravimétricos e de poços tubulares foram utilizados para a análise da estruturação do embasamento na região central da planície costeira do Recife. A interpretação dos mapas gravimétricos Bouguer e Residual mostram três áreas com assinaturas gravimétricas distintas: uma anomalia positiva, alongada e alinhada na direção ENE-WSW que representa a zona de cisalhamento Pernambuco Leste, e duas depressões nas porções norte e sul da área, que representam as Bacias da Paraíba e de Pernambuco, respectivamente. Esta compartimentação está claramente associada com a zona de cisalhamento Pernambuco Leste, que é responsável por dividir essas duas bacias sedimentares. A integração dos mapas gravimétricos com o mapa de profundidade do topo do embasamento apresenta coerência, pois a comparação dos valores da profundidade do topo do embasamento obtidas a partir de poços e as anomalias observadas nos mapas gravimétricos Bouguer e Residual permitiu calibrar a interpretação, e as profundidades eficazes dos poços na região.

\section{Introdução}

O presente estudo foi realizado numa área de aproximadamente $35 \mathrm{~km}^{2}$ geomorfologicamente localizada na planície costeira do Recife (Figura 1). Esta região está geologicamente inserida na zona transição entre duas Bacias Sedimentares (Pernambuco e Paraíba) que são divididas pela Zona de Cisalhamento Pernambuco Leste (ZCPE) (Neves e Mariano, 1999). Os trabalhos publicados que envolvem a área em questão se direcionaram aos aspectos sedimentológicos e estruturais dando especial ênfase aos sedimentos cretáceos que configuram o principal aquífero da região. Este estudo geofísico visa de forma preliminar uma integração de dados gravimétricos terrestres aliados com dados de profundidades de poços que alcançaram o embasamento cristalino. A partir dessa análise, uma interpretação da estruturação do embasamento cristalino será proposta tendo-se como base, as assinaturas gravimétricas juntamente com os dados de profundidades dos poços. Numa visão geológica global, os trabalhos acadêmicos publicados revelam que os sedimentos da Bacia da Paraíba, conforme conceituado por Barbosa (2004), limitam-se ao Sul pela ZCPE, enquanto que os depósitos da Bacia de Pernambuco, de acordo com Lima
Filho (1998), tem como limite a região imediatamente ao Norte da ZCPE.

\section{Metodologia/ Problema Investigado}

A base de dados utilizada neste trabalho faz parte de uma compilação de 47 estações gravimétricas terrestres irregularmente espaçadas que foram levantadas pela UFPE e pela CPRM (Oliveira, 1994) em parceria com o Obsevatório Nacional. O total de 23 dados de poços tubulares também dispostos em uma malha irregularmente espaçada foi compilado por meio de uma série de levantamentos hidrogeológicos. As profundidades do topo do embasamento obtidas através dos perfis litológicos dos poços foram correlacionadas com os mapas gravimétricos. Após as correções e devidas transformações pontuais dos dados gravimétricos em valores de Anomalia Bouguer, estes foram interpolados pelo método da mínima curvatura com espaçamento de $1 / 4$ da distância média entre as estações que foi de $720 \mathrm{~m}$. Os valores de profundidade do topo do embasamento também foram interpolados pelo método de mínima curvatura com 0 espaçamento de $1 / 4$ da distância média entre os poços que foi de $1,5 \mathrm{~km}$. O produto desta etapa foi à geração dos mapas de Anomalia gravimétrica Bouguer e de profundidade do topo do embasamento (Figuras 2 e 3). Através da separação pelo método Gaussiano com comprimento de onda de corte de $5263 \mathrm{~m}$, foi gerado o mapa de anomalia gravimétrica Residual (Figura 4).

\section{Resultados}

A interpretação do mapa gravimétrico Bouguer mostra a presença de uma anomalia positiva, alongada e alinhada na direção ENE-WSW, localizada na porção central, com os valores variando entre 30,6 e $28,8 \mathrm{mGal}$. A partir da anomalia positiva central os valores decrescem, em direção ao norte, de 28,8 a $26,8 \mathrm{mGal}$, da região central para o sul os valores diminuem de 28,8 à $17,8 \mathrm{mGal}$. $\mathrm{O}$ gradiente da porção norte é de cerca de $1 \mathrm{mGal} / \mathrm{m}$ e o da porção sul é de cerca de $5,5 \mathrm{mGal} / \mathrm{m}$. Estas feições indicam claramente a presença da ZCPE como um alto estrutural que separa regiões gravimetricamente distintas a norte (Bacia da Paraíba), com gradiente menos acentuado, e a sul (Bacia de Pernambuco), com um gradiente mais expressivo (Figura 2). O mapa gravimétrico Residual (Figura 4) reforça a interpretação feita a partir do mapa gravimétrico Bouguer. Este mapa evidencia as anomalias superficiais relacionando os baixos gravimétricos a sul e a norte da ZCPE e mostra uma anomalia alongada e positiva que representa a ZCPE, com valores que variam de 3,5 à $0,7 \mathrm{mGal}$. $\mathrm{Na}$ Bacia de Pernambuco, os valores variam de 2,7 à $-1,8$, e na Bacia da Parabaíba, os valores variam de 2,7 à $-0,3$ mGal. 
O mapa do contorno do embasamento gerado com os dados de poços apresentam valores que variam entre 96 $\mathrm{m}$ e $246 \mathrm{~m}$ (Figura 3). Este mapa também mostra a presença de um alto na região central da área de estudo, formado pela ZCPE, e de uma região rebaixada a SE, que representa a Bacia de Pernambuco. A integração dos mapas gravimétricos Bouguer e Residual com 0 mapa de profundidade do topo do embasamento apresentam boa concordância, por exemplo, regiões em que ocorrem valores de anomalias gravimétricas positivas, mostram uma profundidade do topo do embasamento menor (Figuras 2, 3 e 4) e anomalias negativas correspondem a profundidades do topo do embasamento maiores.

\section{Discussão e Conclusões}

Baseando-se na análise interpretativa dos mapas gravimétricos Bouguer e Residual, os mesmos apresentam três regiões com caráter distinto. A região central marcada pela anomalia positiva alongada com direção ENE-WSW, foi interpretada como um alto estrutural formado pela ZCPE. A partir desta porção, duas regiões que partem do centro do mapa para as regiões sul e Norte apresentam valores gravimétricos que decrescem, e que condizem com os baixos relacionados as bacias de Pernambuco e da Paraíba, respectivamente. A ZCPE separa dois domínios geologicamente distintos, confirmando o fato de que a planície costeira do Recife está exatamente na transição entre duas Bacias sedimentares (Bacia da Paraíba a Norte da ZCPE e a Bacia de Pernambuco a Sul da ZCPE).

\section{Agradecimentos}

Ao Departamento de Geologia da UFPE e aos Laboratórios de Sismoestratigrafia, de Geofísica Aplicada e de Geologia Sedimentar e aos colegas de pesquisa.

\section{Referências}

Barbosa, J. A. 2004. Evolução da Bacia da Paraíba durante o Maastrichtiano-Paleoceno: formações Gramame e Maria Farinha, NE do Brasil. Dissertação de Mestrado, Centro de Tecnologia e Geociências, Universidade Federal de Pernambuco, 230 pp.

Barbosa, J.A., Lima Filho, M., Neumann, V.H., Neto, J.C.J., Araújo, J.A.A. 2008. Potencial exploratório das bacias da Paraíba e da Plataforma de Natal. In: Rio Oil \& Gas Conference 2008, Rio de Janeiro, Boletim de Trabalhos Técnicos, 1-8 (IBP_1746).

Costa, 2007. Estudo de identificação de causas de salinização e indicação de processo de obstrução de poços salinizados. COSTA CONSULTORIA. MI/SIH. CPRH-PE. $191 \mathrm{p}$.

Lima Filho, M. F. 1998. Análise Estrutural e Estratigráfica da Bacia Pernambuco. Tese de Doutorado. Instituto de Geociências, Universidade de São Paulo. 139 p.
Neves, S. P.; Mariano, Gorki. 1999. Assessing the tectonic significance of a large-scale transcurrent shear zone system: the Pernambuco lineament, northeastern Brazil. Journao of Structural Geology, v.21,n.10, p.13691383,

Oliveira, R.G. 1994. Levantamento Gravimétrico da Área Sedimentar da Região Metropolitana do Recife. Recife: CPRM/FIDEM. Projeto SINGRE, 38 pp.

Rand, H.M. 1976. Estudos Geofísicos na Faixa Litorânea ao Sul de Recife. Tese (Docente Livre) - Centro de Tecnologia, Universidade Federal de Pernambuco, 101 pp. il. 
José Ricardo Gonçalves Magalhães¹, UFPE; Mário Amilde Valença dos Santos² ${ }^{2}$ UFPE; Tiago Siqueira de Miranda ${ }^{3}$, UFPE;3 José Antônio Barbosa ${ }^{4}$, UFPE; Jefferson Tavares Cruz Oliveira ${ }^{5}$, UFPE

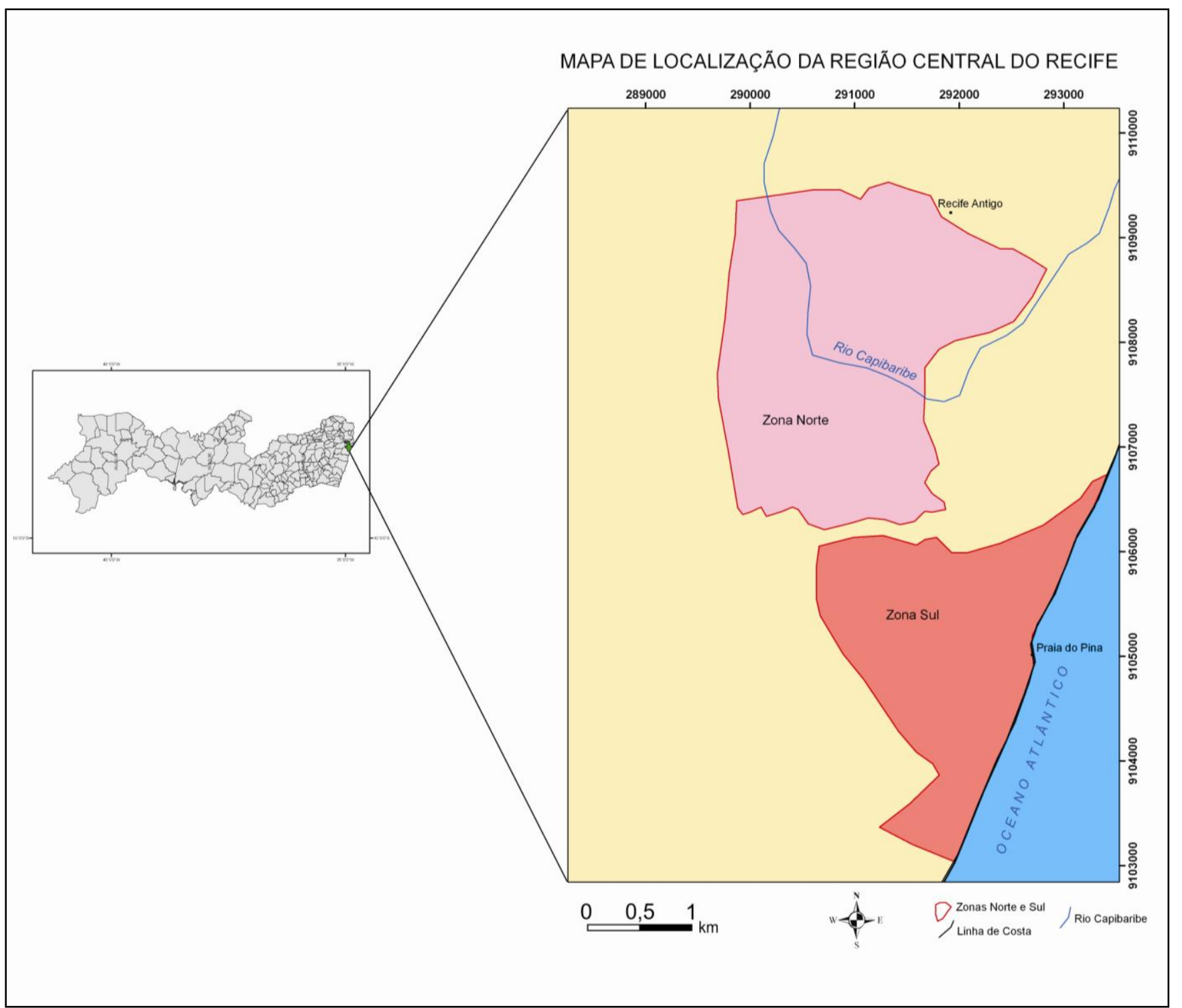

Figura 1: Mapa de localização da área de estudo que está inserida na porção central do Recife. Destaque para a divisão das zonas norte e sul da cidade do Recife. 


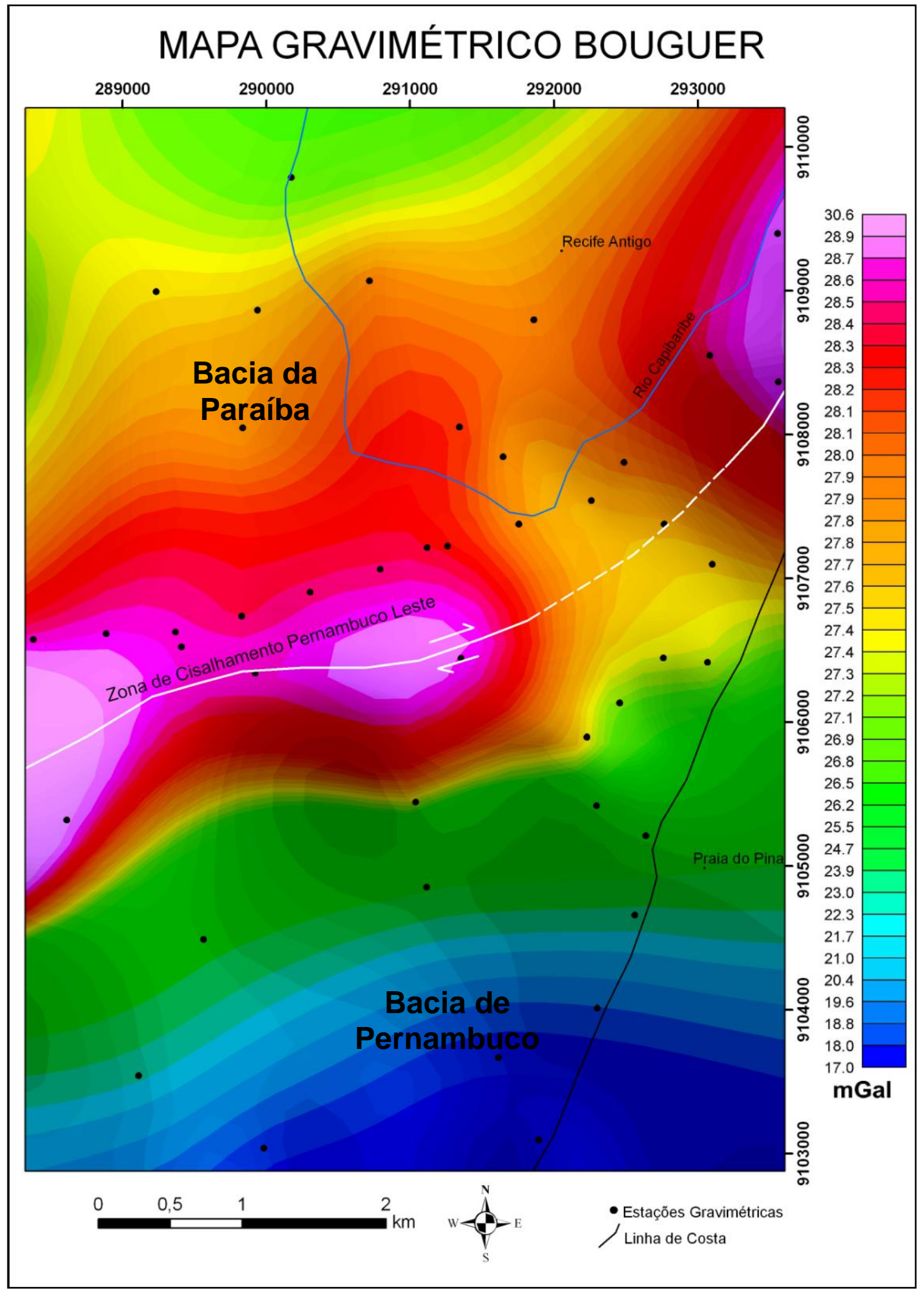

Figura 2: Mapa gravimétrico Bouguer da porção central da planície do Recife. Destaque para a distribuição das estações gravimétricas e da localização das Bacias de Pernambuco e da Paraíba. 


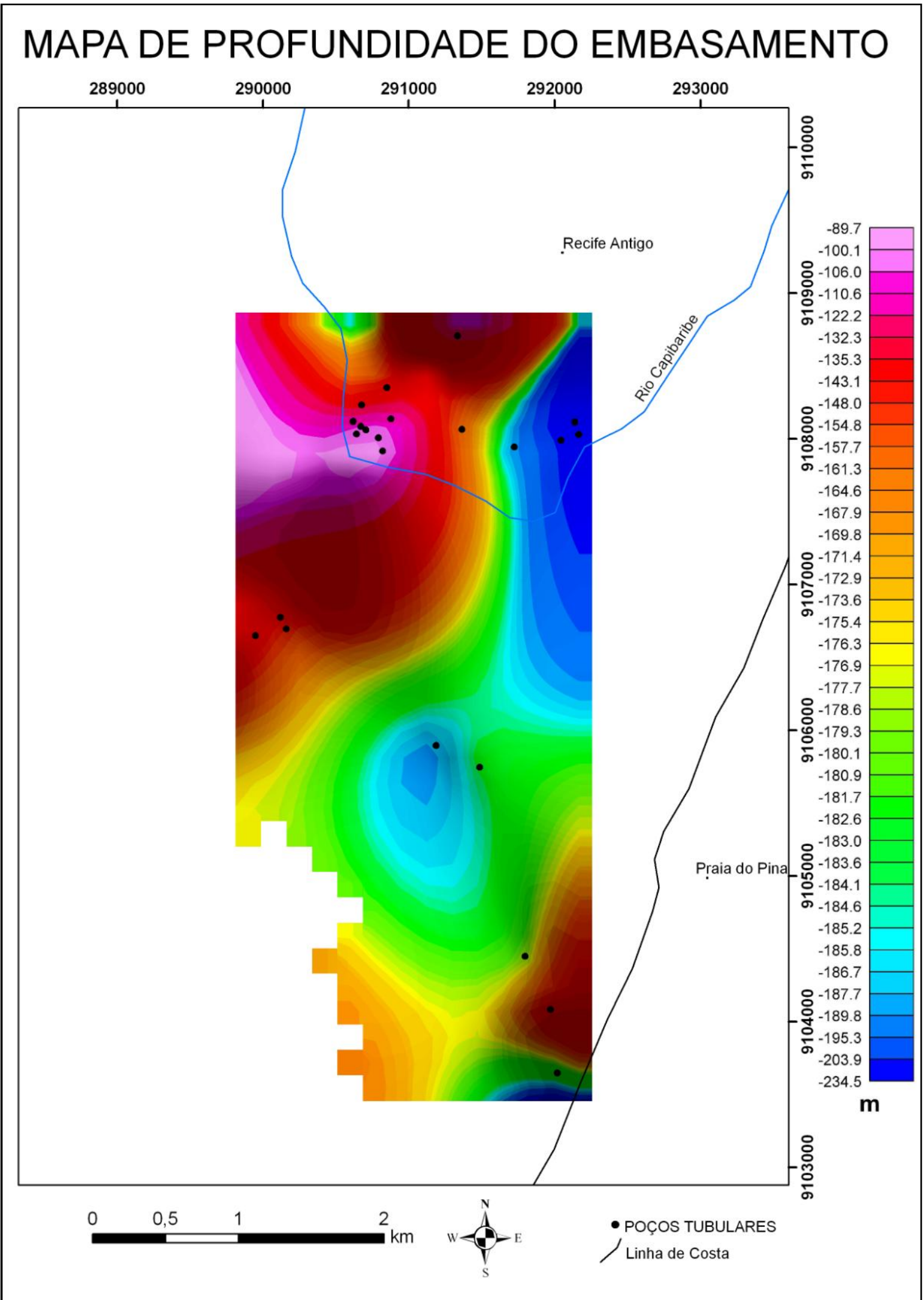

Figura 3: Mapa de Profundidade do Topo do Embasamento da porção central da planície do Recife. Destaque para a distribuição dos poços tubulares levantados. 


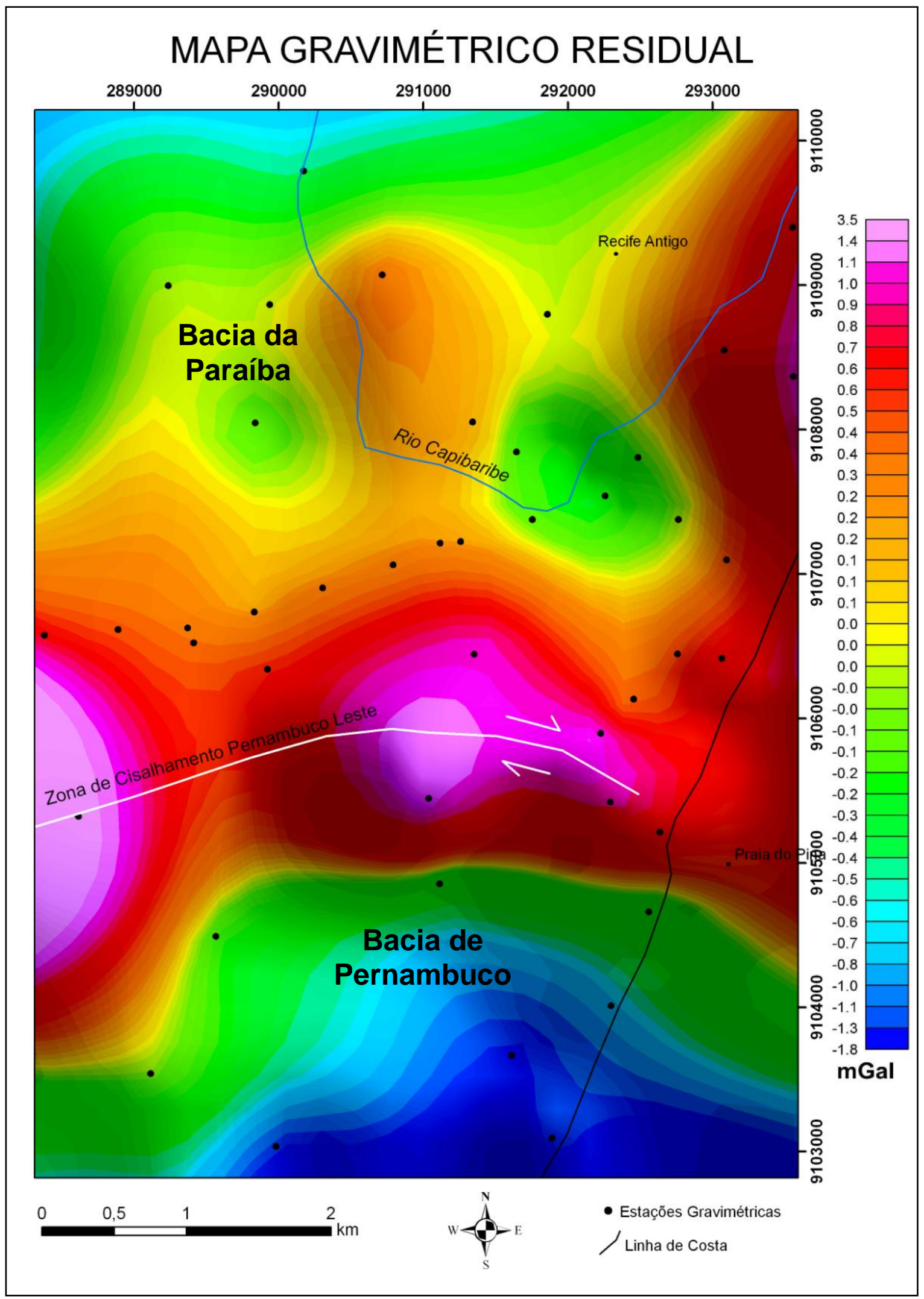

Figura 4: Mapa gravimétrico Residual da porção central da planície do Recife. Destaque para a distribuição das estações gravimétricas e das Bacias da Paraíba e de Pernambuco. 